\title{
Haemophilus influenzae: an underrated cause of vulvovaginitis in young girls
}

\author{
R A Cox
}

\begin{abstract}
Aims-To establish the common pathogens associated with infective vulvovaginitis in young girls in the local population and to determine current management of this condition.

Methods-A prospective laboratory based survey was carried out over 19 months. A questionnaire was then sent to local general practitioners and hospital doctors.

Results-One hundred and six swabs were received during the study period of which $43(40.5 \%)$ yielded organisms recognised as causes of vulvovaginitis. The most common pathogen was group A $\beta$ haemolytic streptococcus (19), with Haemophilus influenzae the second most common (11). Candida was isolated on nine occasions. The users' questionnaire had an overall response rate of $52 \%$. Forty one per cent of respondents nominated candida as the most common cause of this condition. Forty six per cent were aware that $\beta$ haemolytic streptococci caused juvenile vulvovaginitis, but only four (3.6\%) knew that $H$ influenzae was a possible pathogen. The most popular agent for empirical treatment of vulvovaginitis was topical clotrimazole cream, although 24 respondents (22\%) prescribed antibiotics that are active against both group A B haemolytic streptococci and $H$ influenzae.

Conclusions-Although $H$ influenzae is the second most common infective cause of juvenile vulvovaginitis in the local population, most doctors managing these patients were unaware of its importance and may not be prescribing appropriate empirical treatment.

(f Clin Pathol 1997;50:765-768)
\end{abstract}

Keywords: Haemophilus influenzae; juvenile vulvovaginitis

Vulvovaginitis is a common problem in prepubertal girls. Most cases are managed by general practitioners with only the most severe or recurrent cases being referred to hospital specialists. While the majority of cases are said to be caused by poor hygiene, a substantial minority are associated with bacterial infection. Other causes such as threadworms, foreign bodies, and sexual abuse may need to be considered.

Although a number of comprehensive studies have been undertaken in the United
Kingdom and elsewhere, the microbiology of juvenile vulvovaginitis is described poorly in popular textbooks of microbiology, gynaecology, paediatrics, and infectious diseases.

To determine the microbiology and management of infective vulvovaginitis in young girls in the local population a two part study was undertaken. Over a 19 month period, information was collected on all laboratory requests for vulval and vaginal cultures on girls aged 14 years or less. A questionnaire was then sent to all general practitioners and hospital doctors who requested this test to establish current management of this condition.

\section{Methods}

\section{LABORATORY METHODS}

Over a 19 month period the following information was collected on all requests for culture of vulval and vaginal swabs received from girls aged 14 years and under: age, brief clinical details, and source of request (general practitioner or hospital doctor).

All swabs were received in Amies transport medium (Transwabs, Medical Wire, Corsham, Wiltshire, UK) and were cultured on the following: chocolate (heated blood) agar, blood agar (7\% horse blood), and human blood agar (for Gardnerella vaginalis). Swabs were inoculated into Feinberg and Whittington's medium (Unipath, Basingstoke, Hampshire, UK) and a wet preparation examined after 48 hours for candida and Trichomonas vaginalis. In the eighth month of the study, a selective medium for Neisseria gonorrhoeae (brain heart infusion agar with lysed horse blood and VCNT (vancomycin, colistin sulphate, nystatin, trimethoprim) supplement) was added.

Suspected pathogens were identified by standard methods. ${ }^{1}$ Isolates of Haemophilus influenzae were tested for the presence of type $b$ capsular polysaccharide by slide agglutination with specific antiserum.

\section{QUESTIONNAIRE}

After the completion of the laboratory study, a brief questionnaire (fig 1) was sent to 187 general practitioners served by the laboratory and to 25 senior and junior medical staff working in paediatrics and gynaecology.

\section{Results}

\section{LABORATORY STUDY}

One hundred and six swabs from 104 patients were examined by the laboratory during the study period. After selective culture medium for $N$ gonorrhoeae was introduced eight months into the study, 81 swabs were cultured on this 


\section{Speciality:}

Grade:

1. Have you ever sent vaginal or vulval swabs from prepubertal girls for microbiological culture?

2. What pathogens might you expect to identify?

Please list in order of frequency:

Don't know (please tick)

3. If you receive a report identifying a microbial pathogen with sensitivities to antibiotics, would you prescribe one of the antibiotics listed?

4. Would you initiate blind treatment before the laboratory result was returned?

5. If yes, which antibiotic would you choose?

Figure 1 Users'questionnaire.

medium. One hundred swabs (94\%) were received from general practitioners, four from dermatologists, and two from paediatricians. The age range was from 2 weeks to 14 years but $74(71 \%)$ were between the ages of 2 and 7 years (fig 2).

\section{MICROBIOLOGY}

No child had a positive result for $T$ vaginalis, $N$ gonorrhoeae, or $G$ vaginalis. Fifty seven swabs (53\%) yielded skin or bowel flora, 43 (40.5\%) grew organisms recognised as causing vulvovaginitis (table 1 ), and six grew $\beta$ haemolytic streptococci group $\mathrm{B}$, whose role in this condition is unclear. Of the nine swabs that grew candida, two were mixed cultures, one with a group A $\beta$ haemolytic streptococcus and the other with $H$ influenzae. All $H$ influenzae isolates were sensitive to amoxycillin.

\section{QUESTIONNAIRE}

One hundred and eleven completed questionnaires were returned, an overall response rate of $52 \%$. The response rate was higher for general practitioners $(102 / 187 ; 55 \%)$ than for hospital doctors $(9 / 25 ; 36 \%)$.

In answer to the first question, $85(75 \%)$ of the respondents sent vaginal or vulval swabs from prepubertal girls for microbiological cul-

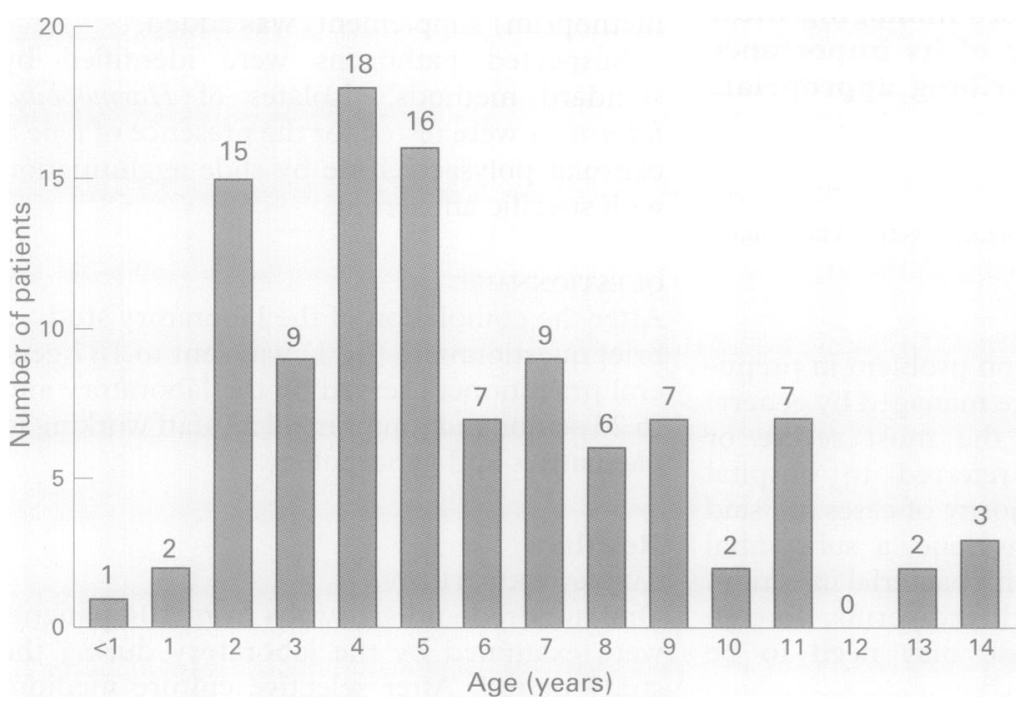

Figure 2 Age of patients at presentation.
Table 1 Pathogenic organisms isolated from prepubertal vulval swabs $(n=45)$

\begin{tabular}{lc}
\hline Organism & Number $(\%)^{\star}$ \\
\hline B Haemolytic streptococci & $19(18)$ \\
Group A & $1(1)$ \\
Group C & $4(3.7)$ \\
Group G† & $11(10)$ \\
H influenzae & $9(8.5)$ \\
Candida & $1(1)$ \\
Streptococcus pneumoniae & $45(42)$ \\
Total & \\
\hline
\end{tabular}

*Percentage of total number of swabs examined (106). †Isolated from the same patient on two occasions.

ture. Twenty five $(22.5 \%)$ had not and one respondent did not answer this question.

The pathogens expected by the respondents are listed in table 2. Candida was the most popular choice as the commonest cause of juvenile vulvovaginitis. "Streptococci", group A streptococci and $\beta$ haemolytic streptococci were correctly identified as the most common cause by $23 \%$. Fifty one ( $46 \%$ ) of the respondents recognised that $\beta$ haemolytic streptococci were pathogens in vulvovaginitis. Those respondents who cited Chlamydia trachomatis and $N$ gonorrhoeae added the qualification that these would be found only in cases of child sexual abuse. Sixteen respondents (14\%) indicated that they did not know which pathogens were associated with juvenile vulvovaginitis.

In answer to question 3, 108 respondents (97\%) would prescribe antibiotics if they received a laboratory report identifying a microbial pathogen and listing sensitivities. Many respondents qualified their answer with: "if symptoms persist or are severe"; two said "not necessarily"; and one respondent would not prescribe antimicrobial treatment.

Forty seven respondents ( $42 \%$ ) would initiate blind treatment but again many qualified their response with the comments: "if symptoms severe" or "if candida suspected".

The agents prescribed for empirical treatment are listed in table 3.

\section{Discussion}

The results of the laboratory study were remarkably consistent with the results of other recent studies into the microbiology of juvenile vulvovaginitis. Donald and colleagues, reviewing isolates from vaginal swabs of children with vulvovaginitis in the Nottingham area over a four year period, found that group A $\beta$ haemolytic streptococci were isolated from $11 \%$ of all vaginal swabs from children. ${ }^{2}$ Other potential pathogens isolated in their study were $\mathrm{H}$ influenzae (5.3\%), candida (2.6\%), and Streptococcus pneumoniae (1\%). Pierce and Hart, in a 33 month prospective study of children presenting to a paediatric accident and emergency department, found that the most common single organism isolated from vaginal swabs was $H$ influenzae (22/190), with streptococci second most common (17/190), and candida a very poor third $(7 / 190) .^{3}$ A study of premenarchal girls in a single group general practice found specific bacteria to be implicated in 10 out of 42 cases that presented over a five and a half year period. ${ }^{4}$ Group A $\beta$ haemolytic streptococci were isolated from $17 \%$ of vulval swabs, 
Table 2 Respondents' answers with respect to the most common pathogens associated with juvenile vulvovaginitis

\begin{tabular}{llllll}
\hline \multicolumn{5}{c}{ Most common cause } \\
\cline { 2 - 6 } Pathogen & 1 & 2 & 3 & 4 & 5 \\
\hline Candida & No(\%) & No(\%) & No(\%) & No(\%) & No(\%) \\
Streps/GAS/BHS & $46(41)$ & $16(143)$ & $4(3.6)$ & $2(1.8)$ & 0 \\
E coli/coliforms & $25(225)$ & $18(16)$ & $7(62)$ & $1(0.9)$ & 0 \\
S aureus & $13(11.6)$ & $13(11.6)$ & $2(1.8)$ & 0 & 0 \\
Anaerobes & $6(5.4)$ & $12(10.7)$ & $5(4.5)$ & 0 & 0 \\
Faecal streps & $3(2.7)$ & $4(3.6)$ & $5(4.5)$ & $1(0.9)$ & 0 \\
GBS & $1(0.9)$ & $4(3.6)$ & $2(1.8)$ & 0 & 0 \\
S pneumoniae & 0 & $1(0.9)$ & 0 & 0 & 0 \\
H influenzae & 0 & 0 & $1(0.9)$ & 0 & 0 \\
G vaginalis/BV & 0 & $4(3.6)$ & 0 & 0 & 0 \\
C trachomatis & 0 & $2(1.8)$ & $1(0.9)$ & 0 & 0 \\
N gonorrhoeae & 0 & $4(3.6)$ & $1(0.9)$ & $2(1.8)$ & 0 \\
Trichomonas & 0 & 0 & $4(3.6)$ & 0 & $2(1.8)$ \\
Threadworms & 0 & $5(4.5)$ & $2(1.8)$ & 0 & $1(0.9)$ \\
\end{tabular}

GAS, group A streptococci; BHS, $\beta$ haemolytic streptococci; GBS, group B steptococci; BV, bacterial vaginosis.

Table 3 Antimicrobial agents used for blind treatment of juvenile vulvovaginitis

\begin{tabular}{lc}
\hline Agent & Number prescribing \\
\hline Clotrimazole & 19 \\
Nystatin & 1 \\
Timodine & 1 \\
Amoxycillin & 12 \\
Coamoxiclav & 11 \\
Penicillin & 6 \\
Erythromycin & 2 \\
Cephalosporin & 1 \\
Metronidazole & 9 \\
Ciprofloxacin & 2 \\
Otherst & 3
\end{tabular}

*Contains hydrocortisone and nystatin. †Broad spectrum, trimethoprim, antihelminth

$H$ influenzae from $5 \%$ and $S$ aureus from $2 \%$. A recent study from East London reported the isolation of group A $\beta$ haemolytic streptococci from $18 \%$ of swabs submitted to a district microbiology laboratory from girls with vulvovaginitis over a two year period. ${ }^{5}$

The pathogenic role of non-capsulate $H$ influenzae was recognised by Farrand who reported a case of haemophilus vaginitis in a four year old child in $1971,{ }^{6}$ but it was not until Mafarlane demonstrated the organism in young girls with vulvovaginitis, but not in controls, that the role of $H$ influenzae in this condition was established. ${ }^{7}$ None of the isolates obtained in the current study agglutinated with type $b$ antiserum, so it is likely that they were non-capsulate. Biotyping was not undertaken at the time, but this is currently being investigated in a new study.

Although many respondents to the questionnaire believed that candida was the most common cause of juvenile vulvovaginitis, the laboratory study confirmed that it was a far less common cause of vulvovaginitis in the prepubertal age group than in women of child bearing age. This has been remarked upon by the authors of other, similar studies. ${ }^{348}$

Despite the use of human blood agar to improve detection of $G$ vaginalis, this organism was not isolated from any of the swabs examined. Although one study showed this to be the most common cause of vulvovaginitis in children subjected to sexual abuse ${ }^{8}$ this finding was not confirmed in another, similar study. ${ }^{9}$
Early studies of juvenile vulvovaginitis emphasise the importance of gonococcal infection, ${ }^{10}{ }^{11}$ but this was not detected in the present study, even after the inclusion of a selective medium. This may reflect the current national decline in cases of gonorrhoea in the adult population. A recent study of young girls, the majority of whom were known or suspected to have been sexually abused, did not detect a single case of gonorrhoea. ${ }^{8}$

The role of faecal flora (coliforms, anaerobes, and faecal streptococci) in the aetiology of juvenile vulvovaginitis is unclear. The proximity of the vulva and anus in young girls means that such a finding may reflect contamination rather than infection.

The laboratory study was undertaken to determine the microbiology of infective vulvovaginitis in young girls and did not, therefore, take into account the contribution of other factors. Two clinical studies emphasised the important contribution of poor hygiene. ${ }^{34}$

The agents chosen by the respondents for empirical treatment of vulvovaginitis reflected their beliefs about the cause of this condition. Topical clotrimazole ointment has a broad spectrum that includes candida and Gram positive cocci. It is unlikely to be adequate for severe bacterial infection. Inadequate treatment may result in persistent or recurrent infection. Twenty six respondents $(23 \%)$ indicated that they would choose an agent that would be effective against both $\beta$ haemolytic streptococci and $H$ influenzae. In our area, $15 \%$ of $H$ influenzae isolates are resistant to amoxycillin, but all isolates in the study were sensitive, so amoxycillin remains the antibiotic of choice for empirical treatment of severe symptoms. The study did not include any follow up of patients, so it is not possible to establish the efficacy of treatment prescribed. It is a matter of some concern that two practitioners would prescribe ciprofloxacin for empirical treatment when it is recognised that this agent should be avoided in children if possible.

A review of current textbooks of microbiology, paediatrics, obstetrics, and infectious diseases shows that juvenile vulvovaginitis is covered poorly and evidence from recent published studies is not referred to. Some textbooks do not mention the condition at all, ${ }^{12-14}$ and others mention only $\beta$ haemolytic streptococci and gonococcal vulvovaginitis. ${ }^{15}$ Paediatric textbooks are similarly unhelpful. ${ }^{16}{ }^{17}$ Feffcoate's principles of gynaecology gives the most comprehensive account, but still fails to mention $\mathrm{H}$ influenzae. ${ }^{18}$ A leading textbook of infectious diseases describes group $\mathrm{A} \beta$ haemolytic streptococci, $N$ gonorrhoeae, $C$ trachomatis, and threadworms as potential pathogens. ${ }^{19}$ Thus, none of the sources of information available most readily to general practitioners and hospital doctors gives a comprehensive account of the present state of knowledge of the bacterial aetiology of vulvovaginitis in children.

In conclusion, this study has demonstrated that the role of specific bacteria (particularly $\beta$ haemolytic streptococci and $H$ influenzae) in the aetiology of infective vulvovaginitis in young girls needs to be appreciated more widely. The 
culture of vulval or vaginal swabs is an essential part of the investigation of this condition. Laboratories should ensure that they include media appropriate for the isolation of $H$ influenzae. Antibiotics should be prescribed according to the laboratory report. Amoxycillin is the agent of choice for severe symptoms that warrant empirical treatment. There is an urgent need for textbooks to update their accounts of juvenile vulvovaginitis to include evidence from recent published studies.

The author thanks local general practitioners and hospital doctors for their unfailing encouragement and support for this study.

1 Barrow GI, Feltham RKA, eds. Cowan and Steel's manual for the identification of medical bacteria. 3rd edn. Cambridge: Cambridge University Press, 1993.

2 Donald FE, Slack RCB, Colman G. Streptococcus pyogenes vulvovaginitis in children in Nottingham. Epidemiol Infect 1991;106:459-65.

3 Pierce AM, Hart CA. Vulvovaginitis: causes and management. Arch Dis Child 1992;67:509-12.

4 Jones $\mathrm{R}$. Childhood vulvovaginitis and vaginal discharge in general practice. Fam Pract 1996;13:369-72.

5 Dhar V, Roker K, Adhami Z, McKenzie S. Streptococcal vulvovaginitis in girls. Pediatr Dermatol 1993;10:366-7.

6 Farrand RJ. Haemophilus influenzae infections of the genital tract. $\mathcal{F}$ Med Microbiol 1971;4:357-8.

MacFarlane DE, Sharma DP. Haemophilus influenzae and genital tract infections in children. Acta Paediatr Scand 1987;76:363-4
8 Steele AM, de San Lazaro C. Transhymenal cultures for sexually transmissible organisms. Arch Dis Child 1994;71: 423-7.

9 Ingram DL, White ST, Lyna PR, Crews KF, Schmid JE, Everett VD, et al. Gardnerella vaginalis infection and sexual contact in female children. Child Abuse Negl 1992;16:84753.

10 Rettig PJ, Nelson JD, Kusmiesz H. Spectinomycin therapy for gonorrhoea in prepubertal children. Am 7 Dis Child 1980;134:359-63.

11 Paradise JE, Campos JM, Friedman HM, Frishmuth G Vulvovaginitis in premenarcheal girls: clinical features and diagnostic evaluation. Pediatrics 1982;70:193-8.

12 Hawkey PM, Lewis DA. Medical bacteriology a practical approach. Oxford: IRL Press at Oxford University Press, 1989.

13 Stokes EJ, Ridgway GL, Wren MWD. Clinical microbiology 7 th edn. London: Butterworths, 1993.

14 Collins CH, Lyne PM, Grange JM. Microbiological methods. 7th edn. London: Butterworths, 1995.

15 Parker MT, Collier LH, eds. Topley and Wilson's principles of bacteriology, virology and immunity. 8th edn. London: Edward Arnold, 1990

16 Houston IB. Disorders of the urogenital system. In: Campbell AGM, McIntosh N, eds. Forfar and Arneil's textbook of paediatrics. 4th edn. Edinburgh: Churchill Livingstone, 1992:1011-84.

17 Sanfilippo JS Gynaecologic problems of childhood. In: Behrman RE, Kliegman RM, Arvin AM, eds. Nelson textbook of paediatrics. 15th edn. Philadelphia: WB Saunders, 1996.

18 Tindall VR, ed. Feffcoate's principles of gynaecology. 5th edn. London: Butterworths, 1987:290-337.

19 Mandell GL, Douglas RG, Bennett JE, eds. Principles and practice of infectious diseases. 4 th edn. New York: Churchill Livingstone, 1995. 